\title{
Muutaman runon ja sävellyksen jäljillä - tekijöitä etsien
}

\author{
Paula Kokkonen, \\ Kirkkonummi \\ paula.kokkonen99@gmail.com
}

\begin{abstract}
Tiivistelmä. Artikkeli käsittelee Heimolasten laulukirjasta ja Sukukansain lauluja -vihkosesta löytyviä kominkielisiä runoja, niiden suomennoksia ja niihin tehtyjä sävellyksiä. Tutkimuksen kohteena on Mihail Lebedevin ja Ivan Kuratovin runot sekä V. I. Lytkinin käännökset J. H. Erkon runoista.
\end{abstract}

Avainsanat: runous, komi, käännös.

\section{Johdanto}

"Kohtalo on erottanut sukulaisheimomme - saman äidin lapset - lopullisesti toisistaan. Suokoon Korkein, että he ainakin hengessä - heimolaistensa lauluissa - voisivat löytää toinen toisensa."

Näihin haikean toiveikkaisiin sanoihin päätti säveltäjä ja kapellimestari Elias Kiianmies (1891-1959) Heimolasten laulukirja -nimisen julkaisunsa esipuheen, joka on kirjassa mukana myös viroksi ja unkariksi käännettynä. Suomi, viro ja unkari ovat tämän WSOY:n vuonna 1935 julkaiseman kirjan pääkielet; pienemmässä määrin ovat mukana liivi ja komi. Kiianmies oli koonnut 112-sivuisen laulukokoelmansa "heimoystäville heimotyössä käytettäväksi”, ja toivoipa hän kirjansa päätyvän oppikirjaksi silloisiin kansa- ja oppikouluihin, jotta lapset voisivat tutustua "heimokansojemme säveliin ja mahdollisesti hieman kieleenkin". Kirja on 1920-1930-luvun heimoaatteen tuotteita.

Heimolasten laulukirjassa on julkaistu suomensukuisten kansojen isänmaallisia lauluja nuotinnoksin ja käännöksin varustettuina ja seuraavasti ryhmiteltyinä:

- Suomalainen osasto - Soome jagu - Finn dalok (19 laulua)

- Eesti jagu - Eestiläinen osasto - Észt dalok (19 laulua)

- Magyar dalok - Madjaarilainen osa - Madjari jagu (20 laulua)

- Livli jag - Liiviläinen osa - Liivi jagu - Lív dalok (kolme laulua)

- Kansallislauluja - Rahvahümnid - Nemzeti hymnuszok (4): Unkarin Hymnusz, Suomen ja Viron yhteinen hymni Maamme - Mu isamaa, Nouse Inkeri ja Komin kansallislaulu Komi skojlun.

Huomioni kiinnittyi erityisesti Komin kansallislauluun, ja sitä oli ruvettava jäljittämään. Mikä se on ja mistä se on päätynyt kääntäjän käsiin ja julkaisuun? 


\section{Mihail Lebedev: Komi zbojlun [Коми збойлун]}

Komin kansallislauluksi on nimetty Heimolasten laulukirjassa sävellys runosta Komi skojlun (po. Komi zbojlun). Sen sanoittajaa eikä säveltäjää ole mainittu, mutta runon kääntäjät mainitaan: suomentajana Tauno E. Eskelinen, virontajana V. Grünthal ja unkarintajana József Miklós. Eskelinen on suomentanut myös julkaisun virolaiset laulut (yhtä lukuun ottamatta) ja yhden liiviläisenkin. Komin kansallislaulun kohdalla on maininta vain lähdekielestä: [käännetty] "syrjäänistä". Kirjan kaikista lauluista annetaan alkukielisen ohessa käännös kahdelle muulle kielelle, Komin hymnistä ja kahdesta liiviläisestä laulusta kuitenkin kolmelle: suomeksi, viroksi ja unkariksi.

Keskusteluni komilaisten kirjailijoiden kanssa johtivat runon Komi zbojlun ('komilainen urheus') jäljille. Kirjoittajaksi paljastui komilainen klassikkokirjailija Mihail Lebedev (1877-1951), kirjailijanimeltään Juś ('joutsen'), jonka kansallishenkinen runo oli julkaistu Komissa vuonna 1914. Runon kuudesta säkeistöstä vain neljä on päässyt laulukirjaan mukaan: 1. ja 3.- 5. Sävellystyö on tehty todennäköisesti Komissa, mutta säveltäjän jäljille ei ole toistaiseksi päästy.

Kansallislauluna Komi zbojlun -sävellystä ei Komissa tunneta - ainakaan yleisesti. Eivätkä lähteet, joissa Lebedevistä tai hänen runoudestaan on kirjoitettu, mainitse asiasta. Komin tasavallan kansallislauluna on kaikunut koko 2000-luvun ajan Varyš poz (Варыш поз 'haukan pesä'), jonka on sepittänyt ja myös säveltänyt kirjailija ja teatterivaikuttaja Viktor Savin (1888-1943), kirjailijanimeltään Njobdinsa Vittor. Varyš poz "päivitettiin" ja virallistettiin kansallislauluksi vuonna 2006. Alkuperäistä runoa on editoinut kirjailija Vladimir Timin ja sovituksesta vastaa säveltäjä Mihail Gertsman. Kansallislaululla on kaksikielisessä tasavallassa kaksi virallista sanoitusta; venäjänkielisen ovat laatineet A. A. Šergina ja A. V. Suvorov. Savinin runo on julkaistu Haukan pesä -nimisenä professori Raija Bartensin toimittamassa ja suomentamassa komilaisen lyriikan antologiassa Käenkukuntayöt (1984: 85).

\section{Ivan Kuratov: Komi kyl [Коми кыл / Коми кыв]}

Vasta 1930-luvulla komilaiset pääsivät tutustumaan lähes sata vuotta aiemmin syntyneeseen runoilijaan Ivan Kuratoviin (1839-1875) ja hänen keskeiseen runoonsa Komi kyl ('komin kieli'), joka oli jo ehditty julkaista Suomessa sekä kominkielisenä vuonna 1903 (suomalais-ugrilaisella transkriptiolla) että suomeksi käännettynä vuonna 1923. Runoa on saatettu jo aiemmin laulaa Komissa kansanomaisesti, mutta ensimmäinen sävellys siitä tehtiin Suomessa. Sittemmin kansallisrunoilijaksi nimetyn Kuratovin vuonna 1857 kirjoittama Komi kyl on löytänyt tiensä vuonna 1929 painettuun vihkoseen Sukukansain lauluja (Suomen Laulun ohjelmistoa N:o 99) ja saanut nimekseen Komin kieli. Nuottivihkonen koostuu neljästä laulusta, joissa näkyy professori, etnomusikologi A. O. Väisäsen (1890-1969) kädenjälki sovittajana, kansanmusiikin kerääjänä ja säveltäjänä. Suomen Laulu ry omistaa tekijänoikeudet näihin Väisäsen sekakuorolle sovittamiin lauluihin. Sukukansain lauluja -vihkoseen valittujen runojen ja sävelmien taustoista kerrotaan seuraavaa (lainaus sivulta 8): 
1. Miksi mun kasvatit? A. O. Väisäsen kirjaanpanema Samaran läänin ersamordvalaisilta v. 1914. Suomennos saman.

2. Vjatkan tytöt on kokoonpantu kahdesta sävelmästä, jotka, samoin kuin runo, on saatu Yrjö Wichmannin julkaisusta "Wotjakische Sprachproben". Suomennos sovittajan.

3. Missä sinut kohdannen? on V. M. Vasiljevin, syntyperäisen tšeremissin, kokoelmasta "Mari muro" (Marilaisia lauluja, v. 1919). Suomennos sovittajan.

4. Sävelmä on sepitetty pentatoniseksi kuten edelliset kansansävelmätkin. Soinnutus, joka näissä sekin on tehty pentatoniseksi, on tässä diatoninen. "Komi kyl” runon sepitti syntyperäinen syrjääni 1. komilainen J. [Ivan] Kuratov (1839-75). O. Mannisen suomennos Kalevalaseuran vuosikirjassa 3.

Neljäs sävelmä paljastuu siis Väisäsen omaksi sävellykseksi. Siitä oli tullut pentatoninen, olihan kolme muutakin sukukansain laulua pentatonista. Tosin pentatoniikka on vierasta komilaiselle kansanmusiikille, joka poikkeaa siten oleellisesti udmurttien, marien ja mordvalaisten kansanmusiikista. Kaikki neljä laulua ovat mukana alkukielisinä ja suomennoksina, joista kolme sovittajan suomentamana, neljäs Otto Mannisen.

Komi kyl -runo (kirjakielisessä muodossaan Komi kyv) kulkeutui Suomeen monia suomalais-ugrilaisia kieliä tutkineen tiedemiehen Yrjö Wichmannin (1868-1932) mukana hänen Komiin 1901-02 suuntautuneen tutkimusmatkansa tuliaisina. Wichmann julkaisi runon Helsingissä Syrjäänin kieltä -nimisessä 8-sivuisessa murrenäytevihkosessaan vuonna 1903. Tämä julkaisu toi ensi kerran päivänvaloon Kuratovia runoutta - ja se tapahtui siis Suomessa. Komi kyl julkaistiin uudelleen T. E. Uotilan komin kielen oppimateriaaliksi kokoamassa Syrjänische Chrestomathiessa (1938: 3233). Otto Mannisen (1872-1950) suomennos Komin kieli julkaistiin Kalevalaseuran vuosikirjassa 3 (1923: 191), josta Väisänen onkin poiminut sen sävellettäväkseen. Runosta on syntynyt sittemmin useita suomennoksia. Komissa Kuratovin runoja alettiin julkaista vähitellen vasta 1920- ja 1930-luvulla, mikä tarkoittaa viitisenkymmentä vuotta kirjailijan kuoleman jälkeen. Vuonna 1979 julkaistussa antologiassa Menam тиzа (Менам муза 'muusani') Komi kyv -runo on itseoikeutetusti ensimmäisenä.

Jo Sukukansain lauluja -vihkosen julkaisuvuonna 1929 nuo edellä mainitut neljä sävellystä myös esitettiin, nimittäin Kalevalajuhlassa ja radiossa. Kansalliskirjaston digitoimista aineistoista löytyy Yleisradion viikoittain ilmestyneet ohjelmalehdet; vuoden 1929 n:rossa 8 kerrotaan, että tulevana kalevalanpäivänä, torstaina 28.2.1929 kuullaan klo 20.00 Kalevalaseuran Kalevalajuhla [Helsingin] yliopiston juhlasalista radioituna. Lähes kaksituntisen ohjelman aikana oli luvassa mm. sekakuorolaulua Suomen Laulun esityksenä Heikki Klemetin johdolla. Suomen Laulu esitti "neljä volgalaisten sukukansain laulua", jotka on sovittanut (ja yhden säveltänyt) A. O. Väisänen. Tuo erikseen mainittu "yhden säveltänyt" oli Väisäsen sävellys Komin kieli. (Oikaisuna sanottakoon, että komilaiset ja udmurtit eivät ole volgalaisia vaan permiläisiä kansoja.)

Väisäsen yhteen saattamat neljä laulua käsitetään useimmiten yhdeksi ohjelmanumeroksi. Vaasan kaupungintalossa 22.4.2004 järjestetyssä kevätkonsertissa Vaasan ylioppilaskuoro ja nuorisokuoro esittivät Sukukansain lauluja György Kádárin ja Anne Tienhaaran johdolla. Ohjelma - mordvalainen, udmurttilainen ja komilainen laulu 
(marilainen laulu ei ole mukana) - on kuunneltavissa neljän minuutin mittaisena esityksenä osoitteessa: https://www.youtube.com/watch?v=eC4-_gFQ3P0.

Väisäsen sävellys Komin kieli on esitetty myös runon kotikonnuilla Syktyvkarissa Suomalais-ugrilaisessa kulttuurikeskuksessa 6.12.2000 Suomen itsenäisyyspäivälle omistetun juhlan ohjelmanumerona. Komilainen (ižmalainen) oopperalaulaja Vasili Ročev esitti laulun Tatjana Loginovan säestäessä pianolla. - Ei ihan kotoisen tuntuista komilaisille korville, kommentoivat esiintyjät sävellyksen pentatoniikkaa. Illan esitys luokiteltiin A. O. Väisäsen sävellyksen kantaesitykseksi Komissa. Valitettavasti esitystä ei nauhoitettu.

Komi kyv -runo on sävelletty myöhemmin myös Komissa. Komi śylankyvjas (Коми сьыланкывъяс 'komilaisia lauluja') -nimisessä laulukirjassa se esitellään kuoronjohtaja A. Katorgininin (1901-1981) sävellyksenä. Samassa kirjassa on myös V. Savinin runo ja sävellys Varyš pož, ei vielä kuitenkaan Komin hymninä. (1984: 56; 38-39.)

Ensimmäinen kominkielinen ooppera on nimeltään Kuratov. Sen on säveltänyt Syktyvkarissa syntynyt, Lontooseen sittemmin siirtynyt Sergei (Serge) Noskov (s. 1956). Runoilija Albert Vanjejev (1933-2001) oli kirjoittanut libreton jo vuonna 1984, mutta säveltäjää jouduttiin etsimään kauan. Noskov tarttui Vanjejevin librettoon ja muokkasi siitä mieleisensä, ja kaksinäytöksinen Kuratov-ooppera valmistui vuonna 2009. Siinä kerrotaan kansallisrunoilijan lyhyt, mutta värikäs elämäntarina, ja yhtenä aariana kuullaan Komi kyv. Ensi-iltansa ooppera sai Syktyvkarissa Komin tasavallan valtiollisessa ooppera- ja balettiteatterissa 2. lokakuuta 2009. Komi kyv -aarian voi kuunnella osoitteessa: https://www.youtube.com/watch?v=n32kZj4bY0I.

\section{V. I. Lytkin ja kominnokset J. H. Erkon runoista Laulu Wuoksella, Nyt ja sitten ja Missä kukka}

Eriskummallista on J. H. Erkon (1849-1906) runon Missä kukka päätyminen komilaisen kielitieteilijän ja kirjailijan Vasili Lytkinin (1895-1981) runoksi. Opiskellessaan Moskovasssa 1920-luvulla Lytkin oli tutustunut suomalaiseen kirjallisuuteen. Vuosina 1926-1927 hän jatkoi opintojaan Helsingissä, ja tuolloin 10 kuukauden aikana kielitieteellisten opintojensa ohessa hän kirjoitti lähes 30 runoa. Hän oli haeskellut käännettävää myös suomalaisesta runoudesta, mutta mieleistä ei oikein tahtonut löytyä. Kolme runoa Erkon tuotannosta hän on kuitenkin komintanut. Ne ovat Laulu Wuoksella, Nyt ja sitten sekä Missä kukka; näistä kaksi löytyy vuonna 1917 painetusta M. Gorkin ja V. Brjusovin toimittamasta Suomen kirjallisuutta esittelevästä kokoomateoksesta Сборникъ Финляндской литературы. Teoksen tiedetään olleen udmurttilaisen kirjailijan Kuzebai Gerdin kirjahyllyssä. Gerd ja Lytkin opiskelivat samoihin aikoihin Moskovassa, ja ystävänsä luona Lytkin on voinut tutustua tuohon teokseen ja valita venäjäksi käännetyistä Erkon runoista kaksi: Laulu Wuoksella, jonka hän kominsi jo Moskovassa opiskellessaan, ja Nyt ja sitten, jonka hän on kääntänyt komiksi ilmeisesti Suomessa. Helsingistä Lytkin siirtyi vuonna 1927 pariksi vuodeksi Budapestiin, jossa väitöskirjatyön ohessa syntyi sielläkin runokäännöksiä: kymmenkunta kominnosta unkarilaisen runoilijan Sándor Petőfin rakkauslyriikasta. 
Ensimmäisestä, vuonna 1924 komintamastaan runosta Lytkin mainitsee alkuperän: "suomalaisen runoilijan Erkon Vuoksen laulu (oik. Laulu Wuoksella) mukaan". Hän on siis mukaellut runoa ja antanut sille nimeksi Töv nyr (Тӧв ныр 'tuulispää'). Erkon runon Vuoksi ja Saimaan aallot ovat muuttuneet Lytkinillä Komin parma(-metsä)ksi. Runon isänmaallinen sanoma tuli siten kotoutettua komilaismaisemiin. (Erkko 1881: 116; Lytkin 1985: 131-132.)

Toisen J. H. Erkon runon Nyt ja sitten kokoelmasta Uusia Runoelmia (1885: 131) Lytkin on kääntänyt vuonna 1927. Erkosta ei ole mainintaa; kominnos Öni da mödyś (Ӧні да мӧдысь 'nyt ja toisen kerran') ilmoitetaan tehdyn "suomen kielestä" (Lytkin 1985: 132). Lytkinin käännös ei poikkea kovinkaan merkittävästi Erkon alkuperäisrunosta: runoilija kaipaa äidin ja kodin suomaa turvaa maailmalla, jossa kohtelu on nuivaa ja apu usein tiukassa. Maailmalla, Münchenissä, oli Erkko kirjoittanut runonsa, niin ikään maailmalla, joko Suomessa tai Unkarissa, oli myös Lytkin kääntäessään runoa komiksi.

Kolmas Lytkinin kääntämä Erkon runo yllättää: se on kulkeutunut Komissa julkaisusta toiseen Lytkinin omana runona. Tarkistukseni osoitti, että hänen ensimmäisessä runokokoelmassaan vuodelta 1929 runo Кöni dzoridz (Кӧні дзоридз) oli julkaistu ilman merkintää lähteestä, Erkon Missä kukka -runosta. Kääntäjä tiesi varmasti runon alkuperän, mutta kenties se "vain jäi” merkitsemättä käännöksen yhteyteen. Sama runo on mukana myös julkaisussa Dzordzav žö, Коті ти (Дзордзав жӧ, Коми му 'kukoista, Kominmaa'), johon on koottu kirjailija Lytkinin runoutta ja proosaa sekä käännöksiä (1985: 96). Julkaisun laatijaa kirjailija G. I. Torlopovia ei käy syyttäminen kömmähdyksestä, sillä tuota Erkon runoa on pidetty Komissa jo aiemminkin Lytkinin runona, vaikka se ei tyyliltään muistutakaan hänen runouttaan.

Missä kukka on 13. runo Erkon 22 runoa sisältävästä Paimenelta-nimisestä pastoraali-idyllien sikermästä, joka on julkaistu kokoelmassa Runoelmia (1870: 68). Erkko on kirjoittanut runonsa ennen kuin Lytkin oli syntynytkään, joten plagiointisuunta on kiistaton. Miten Il'l'a Vaś (Lytkinin kirjailijanimi) on runon löytänyt, jää epäselväksi. Ehkä se tuli hänen eteensä suomen oppitunneilla Helsingissä. Kokonsa ja selkeän sanomansa vuoksi runoa on käytetty paljon suomen kielen opetuksessa. Lyhyenä aforismirunona Missä kukka on myös kiitollinen käännettäväksi. Lytkinin kominnos on pääosin sanatarkka, vain Erkon viimeiset säkeet Missä lempi / siellä autuus ovat saaneet Lytkiniltä selkeämmän muodon 'missä rakkaus / onni ei sammu'.

Missä kukka

Siellä kesä,

Missä tähti,

Siellä taivas,

Missä lempi,

Siellä autuus.

(Erkko 1870: 68)
Кӧні дзоридз,

Сэні гожӧм.

Кӧні кодзув,

Сэні енэж.

Кӧні муслун -

Шуд оз куслы.

(Lytkin 1985: 96 ja 1929: 185) 
Tämä artikkeli pohjautuu kirjoittajan kolmeen aiempaan artikkeliin, joita on päivitetty uusin tiedoin:

1. 1999: Илля Васьлӧн финн кывйысь кывбурьяс комиӧдӧм. В.И. Лыткин $и$ финно-угорский мир. Сборник статей. Материалы международной научной конференции, посвященной 100-летию со дня рождения выдающегося коми поэта, философа и ученого В.И. Лыткина (Сыктывкар, 6-9 февраля 1996). Сыктывкар: Министерство по делом национальностей Республики Коми, Коми научный центр УрО Российской академии наук. 145-149.

2. 2008: Суомиысь аддзӧм сьыланкывъяс. Apm 2/2008. Республиканский литературно-публицистический, историко-культурологический, художественный журнал. Сыктывкар. 189-191.

3. 2009: V. I. Lytkin käänsi J. H. Erkkoa komiksi. Suomalais-Ugrilaisen Seuran Aikakauskirja 92. Helsinki. 236-240.

\section{Lähteet}

1. Erkko [J. H.] 1870: Runoelmia. Helsinki: Suomalaisen Kirjallisuuden Seura.

2. Erkko, J. H. 1881: Valikoima Runoelmia. Helsinki: K. E. Holm.

3. Erkko, J. H. 1885: Uusia Runoelmia. Porvoo: Werner Söderström.

4. Heimolasten laulukirja - Hõimulaste laulik - Dalbokréta. Toimittanut Elias Kiianmies. Helsinki - Porvoo: WSOY. 1935.

5. Koтi śylankyvjas = Коми сьbыланкывъяс. Сборник. Сборниксӧ лӧсьӧдіс П. И. Чисталев. Сыктывкар: Коми книжнӧй издательство. 1984.

6. Käenkukuntayöt. Komien lyriikkaa. Toimittanut ja suomentanut Raija Bartens. Suomalaisen Kirjallisuuden Seuran toimituksia 414. Pieksämäki: Suomalaisen Kirjallisuuden Seura. 1984.

7. Lebedev 1914 = Лебедев, Михаил: Коми збойлун. Комі мойдан і сьылан кывъяс. (Зырянскія сказки и пъсни). Чукӧртъіс А. А. Цембер. Устьсысольскъ.

8. Lytkin 1929 = Иљља Bag: Кьввбурјас. Стікотворењњӧја. Сыктывdінкар: Комі њіга лезанін

9. Lytkin 1985 = Лыткин, В. И.: Дзордзав жё, Коми му. Кывбуръяс, поэмаяс, мойдъяс, висьтъяс. Составитель Г. И. Торлопов. Сыктывкар: Коми книжнӧй издательство.

10. Manninen, O. 1923: Syrjääniläisiä kansanrunoja. Kalevalaseuran vuosikirja 3. Porvoo: WSOY. 184-191.

11. Menam тиza = Куратов, Иван 1979: Менам муза-Моя муза. Художественнӧй гижӧд чукӧр. Сыктывкар: Коми книжнӧй издательство.

12. Noskov, Serge[i]. <https://en.wikipedia.org/wiki/Serge_Noskov> 20.2.2021.

13. Sukukansain lauluja. Sekakuorolle sovittanut ja säveltänyt A. O. Väisänen. Suomen Laulun ohjelmistoa N:o 99. Helsinki. 1929.

14. Uotila T. E. 1938: Syrjänische Chrestomathie mit grammatikalischem Abriss und etymologischem Wörterverzeichnis. Apuneuvoja suomalais-ugrilaisten kielten opintoja varten VI. Helsinki: Suomalais-Ugrilainen Seura.

15. Wichmann, Yrjö 1903: Syrjäänin kieltä. Helsinki: Suomalaisen Kirjallisuuden Seuran Kirjapaino Osakeyhtiö.

16. Yleisradio. Radiokuuntelijan viikkolehti n:o 8, 1929. Julkaisija Suomen Yleisradio. <https://digi.kansalliskirjasto.fi/aikakausi/binding/908499?page=11> 14.2.2021. 